\title{
A HILBERT-TYPE INEQUALITY
}

\author{
PRABIR BURMAN
}

Abstract. There are many versions of inequalities due to Hilbert and Hardy. Many extensions to nontrivial cases are now available. We present and derive a new Hilbert-type inequality for both sums and integrals. In our setup, the matrix elements associated with the quadratic form are ratios of differences of powers of an increasing function. This inequality contains some known results as special cases.

Mathematics subject classification (2010): Primary 26D15, Secondary 40G99. tegrals.

Keywords and phrases: Hilbert inequality, Hardy inequality, Hilbert-type inequality for sums and in-

\section{REFERENCES}

[1] M. Krnić, J. Pecarić, P. Perić, And P. Vuković, Recent Advances in Hilbert-type Inequalities, Element, Zagreb, (2012).

[2] M. KRNIĆ, A refined discrete Hilbert inequality obtained via the Hermite-Hadamard inequality, Comp. and Math. Appl., 63, 1587-1596, (2012).

[3] G. H. Handley, Hilbert and Hardy type inequalities, Ph. D. Dissertation, University of Melbourne, (2006).

[4] G. H. Hardy, J. E. Littlewood, and G. Polya, Inequalities, Paperback Edition, Cambridge University Press, Cambridge, (1988).

[5] H. L. Montgomery, and R. C. Vaughan, Hilbert's inequality, J. London Math. (2) Soc. 8, 73-82, (1974).

[6] B. YANG, A Survey of the Study of Hilbert-type Inequalities With Parameters, Advances In Mathematics, Vol. 38, 257-268, (2009).

[7] B. C. YANG, Discrete Hilbert-type Inequalities, Bentham Science Publishers Ltd., (2011). 